\title{
The Vocational ID - connecting Life Design Counselling and Personality Systems Interaction Theory
}

Marc Schreiber $^{\mathrm{a} *}$, Adrian Gschwend ${ }^{\mathrm{a}}$, and Marie-Louise Susanne Iller ${ }^{\mathrm{a}}$

${ }^{a}$ IAP Institute of Applied Psychology, Zurich University of Applied Sciences (ZHAW)

*Correspondence concerning this article should be addressed to Marc Schreiber, IAP

Institute of Applied Psychology, Zurich University of Applied Sciences (ZHAW),

Pfingstweidstrasse 96, 8005 Zurich, Switzerland, marc.schreiber@zhaw.ch

The Version of Record of this manuscript has been published and is available in British Journal of Guidance and Counselling, 25 Oct 2018,

https://www.tandfonline.com/doi/full/10.1080/03069885.2018.1538495. 


\title{
The Vocational ID - connecting Life Design Counselling and Personality Systems Interaction Theory
}

\author{
We introduce the Vocational ID that integrates linguistic and visual representations \\ of a career counselling client's self. Based upon findings from the Life Design \\ paradigm [Savickas, M. L., Nota, L., Rossier, J., Dauwalder, J.-P., Duarte, M. E., \\ Guichard, J.,...van Vianen, A. E. M. (2009). Life designing: A paradigm for career \\ construction in the twenty-first century. Journal of Vocational Behavior, 75(3), \\ 239-250. doi:10.1016/j.jvb.2009.04.004] and the Personality Systems Interaction \\ theory [Kuhl, J. (2000b). The volitional basis of personality systems interaction \\ theory: Applications in learning and treatment contexts. International Journal of \\ Educational Research, 33(7-8), 665-703. doi:10.1016/S0883-0355(00)00045-8], \\ the Vocational ID facilitates working on clients' vocational identity. In this article, \\ we present the theoretical framework, its practical applications, and a case study.
}

Keywords: Career construction interview (CCI), life design, PSI theory, volitional control, self-growth

\section{Introduction}

We developed the Vocational ID as a counselling tool and framework that integrates linguistic and visual representations of a career counselling client's self and vocational identity. The Vocational ID serves primarily to facilitate career counselling from the Life Design perspective, especially for working with the Career Construction Interview (CCI; Savickas, 1989, 2015b), a method derived from the Career Construction Theory (Savickas, 2011a, 2013, 2015b). However, it also easily connects to many other theoretical approaches and counselling methods. In presenting the Vocational ID, we especially refer to and combine two approaches that both focus on career counselling clients' self and identity: (1) The Life Design perspective (Savickas, 2011c, 2012a; Savickas et al., 2009) and (2) Kuhl's (Kuhl, 2000a, 2000b, 2001) Personality Systems Interaction (PSI) theory. 
The Life Design perspective includes reviewing and revising a client's identity narrative. In following Kuhl's theory for integrating motivational and volitional aspects, we focus on the interplay of clients' cognitive and affective processes associated with career development. Kuhl's (2000a, 2000b, 2001) PSI theory distinguishes between analytic and holistic information processing (Kazén, Kuhl, \& Quirin, 2015) and aims at fostering volitional control (also self-control) and self-growth (also self-regulation) (Alsleben \& Kuhl, 2011). Broonen (2015) illustrated the value of the PSI theory for vocational theory and practice: 'In the case of difficult intentions in counselling practice, concerned participants could benefit from an approach that considers differential emotional responsiveness as an important parameter of individual functioning of self-control and self-regulation' (p. 83). We want to follow up on these thoughts and - with our Vocational ID - establish a career counselling tool that facilitates working with both the Life Design perspective and the PSI theory. We will explain and illustrate that the two approaches play different roles during different phases of the career counselling process: The Life Design focus on reconceptualising a client's identity narrative comes first, followed by PSI theory methods that foster a deeper understanding of the motivational and volitional processes that clients undergo when making decisions (deciding) and performing actions (doing) based on their reconceptualised identity narrative. Used together, the two approaches are a powerful and creative tool for the career counselling process.

We will first outline the basic theory behind the two approaches and thereby emphasize the underlying processes of self-construction, self-growth, and identity. Then we will introduce the Vocational ID with a special focus on its practical relevance in career counselling. To further demonstrate the practical applications of the Vocational 
ID, we will present a case study that highlights specific aspects of both the Life Design perspective and the PSI theory.

\section{Life Design perspective and Career Construction Interview (CCI)}

The Life Design perspective recognises the challenges of the twenty-first century labour market and offers a new paradigm for career interventions that highlights subjective narrative truths instead of objective scientific facts (Savickas et al., 2009). Life Design sees career as a repeated transition and non-linear progression within an unforeseeable and unpredictable working world that requires great flexibility and adaptability. This results in career development best being described as a unique and individual process. Savickas (2012a, 2015a) depicts Vocational Guidance (guiding), Career Education and Coaching (developing), and Life Design (designing) as three different paradigms for career interventions. Industrialisation and urbanisation introduced a need for Vocational Guidance, whereas specialisation and the rise of hierarchical, multinational organisations saw Career Education and self-actualisation as a complementary method of career intervention. Life Design as a third paradigm answers needs that have newly arisen through the changes of the postmodern world of work. Table 1 contains the theoretical framework of the Life Design perspective including reference to those questions of the CCI that can be attributed to one of the three paradigms.

From a Life Design perspective, Savickas (2011c, 2012a; Savickas et al., 2009) emphasizes the individual's own self-making, identity shaping, and career construction as crucial for successful career development. Therefore, he developed the Career Construction Interview (CCI; Savickas, 1989, 2015b), a semi-structured interview technique designed to clarify specific career concerns, to identify idiosyncratic life themes, personality characteristics and manifest interests of clients and, finally, to foster their career construction and work-life management. The CCI is a narrative and 
constructionist method based on the Life Design paradigm that with its six open questions also attends to Vocational Guidance and Career Education. The Life Design counselling process, according to the Career Construction Theory (Savickas, 2011a, 2013, 2015b) and performed with the CCI, consists of four phases: construction, deconstruction, reconstruction, and co-construction (Savickas, 2011a, 2012a).

Table 1. Theoretical framework of the Life Design perspective including reference to the CCI questions.

\begin{tabular}{|l|l|l|l|}
\hline \multicolumn{1}{|c|}{ Paradigm } & $\begin{array}{l}\text { Vocational } \\
\text { Guidance }\end{array}$ & $\begin{array}{l}\text { Career Education } \\
\text { and Coaching } \\
\text { (Career } \\
\text { Development) }\end{array}$ & $\begin{array}{l}\text { Life Design } \\
\text { (Career } \\
\text { Counselling) }\end{array}$ \\
\hline $\begin{array}{l}\text { Facet of the self / } \\
\text { science of the self } \\
\text { (Savickas, 2011b, } \\
\text { 2011d, 2012a) }\end{array}$ & $\begin{array}{l}\text { Actor, object / } \\
\text { objective } \\
\text { personality } \\
\text { (objective scores) }\end{array}$ & $\begin{array}{l}\text { Agent, subject / } \\
\text { subjective } \\
\text { personhood } \\
\text { (subjective self- } \\
\text { estimates) }\end{array}$ & $\begin{array}{l}\text { Author, project / } \\
\text { identity } \\
\text { (narratives) }\end{array}$ \\
\hline $\begin{array}{l}\text { Counselling focus } \\
\text { (Savickas, 2015a) }\end{array}$ & $\begin{array}{l}\text { Matching, } \\
\text { guiding, advising, } \\
\text { placing }\end{array}$ & $\begin{array}{l}\text { Self-actualisation, } \\
\text { developing, } \\
\text { educating, coaching, } \\
\text { facilitating, } \\
\text { psychological } \\
\text { counselling }\end{array}$ & $\begin{array}{l}\text { Self-construction, } \\
\text { designing, healing }\end{array}$ \\
\hline $\begin{array}{l}\text { Perspective } \\
\text { (Savickas, 2015a) }\end{array}$ & Empiricism & Humanism & Constructionism \\
\hline CCI question & $\begin{array}{l}\text { Question 2: Early } \\
\text { childhood role } \\
\text { models }\end{array}$ & $\begin{array}{l}\text { Question 3: } \\
\text { Preferred magazines, } \\
\text { TV shows, websites }\end{array}$ & $\begin{array}{l}\text { Favourite book or } \\
\text { movie }\end{array}$ \\
\hline
\end{tabular}

The process starts with the counsellor asking the client the first, introductory question: How can I be useful to you as you construct your career? After identifying the counselling concern and the problem narrative, the construction phase begins by the 
counsellor asking the client questions about childhood role models (question 2), preferred magazines, TV shows, or websites (question 3), current favourite story from a book or movie (question 4), favourite motto (question 5), and early childhood recollections (question 6). In the second, deconstruction phase, the counsellor detects in the client's answers patterns of dominance, dissociation, or disorganisation that create expectancies, biases, and feelings that constrain meaning-making options and disrupt the individual's ability to adapt to vocational development tasks, occupational transitions, and work trauma. The counsellor then discusses with the client how a different perspective and adding new meaning to these beliefs might help overcome these self-limitations (Savickas, 2012a). Subsequently, the central meanings from the answers to questions 2 to 6 are extracted. Having gathered these micronarratives, they are then combined and reconstructed into a large, unified life portrait, also referred to as identity narrative, or macronarrative. This development of the life portrait represents the third, reconstruction phase. The life portrait comprises the subjective representations of the client's explicit occupational plot, implicit career theme, and character arc. According to Savickas (2012a), the occupational plot adds causality to the client's story, whereas the implicit career theme adds meaning to it, and the character arc shows how a person changes over time. This identity narrative provides orientation and explanation concerning the client's past, present, and future and serves as a compass for the next steps. The fourth, coconstruction phase, begins with the presentation, differentiated examination, and modification of the macronarrative together with the client. The results are applied to the client's counselling concern, and future plans (deciding) including concrete next steps (doing) are worked out.

\section{Identity and self-construction from a Life Design perspective}

Savickas (2012a) differentiates between self and identity. Compared to identity, self is 
more stable over the lifetime and therefore serves as a compass guiding the individual through upcoming challenges. Identity continuously adapts to a person's social roles and life experiences. Career counselling from a Life Design perspective supports clients to identify their core self and further develop their vocational identity in accordance with the self. The vocational identity is very closely related to other facets of an individual's identity such as family life, leisure time, and spirituality. Savickas emphasizes selfconstruction as especially effective for successful career development in a world full of transitions and uncertainties such as the current working world. As stability is oftentimes no longer provided by the labour market, clients seek steadiness at the core of their self by identifying the vital aspects of that self.

Working with the CCI addresses the self in different ways and connects these different facets by constructing the life portrait of the client: self as actor (representing Vocational Guidance), self as agent (representing Career Education and Coaching/Career Development), and self as author (representing Life Design/Career Counselling) (Savickas, 2011b, 2015a). In doing so, Savickas refers to McAdams and Olson (2010), who state that the development of the different selves is connected to different life stages:

As it develops over the human life course, personality may be viewed as a constellation of dispositional traits (the person as actor), characteristic adaptations (the person as agent), and integrative life stories (the person as author) situated in time and culture (p. 536).

According to Savickas (2012a) the counsellor takes an active role in the deconstruction process and the reconstruction of the client's life portrait: 'Having reconstructed an identity narrative from the client's micronarratives, the counsellor then presents to the client a draft of her or his life portrait, including the occupational plot, career theme, and character arc' (p. 16). In our practical work, we ascribe responsibility to counsellors for guiding the structured process, whereas the client is the ultimate 
authority for all personal aspects of deconstruction, reconstruction, and co-construction. We consider clients as being the experts of their own lives and therefore invite them to construct their life portrait in collaboration with the counsellor. To facilitate this process and to visualize the life portrait, we developed the Vocational ID presented in this article.

\section{Personality Systems Interaction theory (PSI)}

Kuhl's (Kuhl, 2000a, 2000b, 2018) Personality Systems Interaction theory (PSI theory) explains differences between persons in behaviour not only by differences in mental content (e.g. beliefs, expectancies, intentions), but first and foremost by the interplay of four cognitive-emotional macrosystems: Intention Memory (IM), Intuitive Behaviour Control (IBC), Extension Memory (EM), and Object Recognition (OR). Further, PSI theory postulates that this interplay is influenced by affect-regulation. By definition, each system is associated with a certain affective state and it is assumed that changes in affect enable the activation and deactivation of the systems and the exchange of information between them. In this article, we will illustrate a simplified version of the theory and outline those aspects of PSI theory that are most crucial for working with the Vocational ID. Table 2 summarises these key aspects.

In addition to the distinct functionality of each macrosystem, which will be described further down, the four macrosystems differ in processing mode and processing level. Not unlike the Jungian typology, PSI theory differentiates between analytic thinking and holistic feeling as processing modes. Two of the systems, EM and IBC, function on a primarily intuitive and holistic level, whereas the other two systems, IM and OR, operate predominantly rationally and analytically. Based on empirical findings and incorporating neurobiological evidence, the PSI theory assumes different functional characteristics of the brain hemispheres and consequently locates the four different macrosystems in their respective hemispheres (Kazén et al., 2015; Kuhl, 2018; Quirin, 
Meyer, et al., 2013; Quirin, Gruber, Kuhl, \& Düsing, 2013): Explicit and analytic, sequential information processing in the left hemisphere (IM and OR) versus mainly implicit and holistic, parallel information processing in the right hemisphere (EM and IBC). This resembles McGilchrist (2009), who supposes that the left hemisphere operates narrowly, sharply, focused, and with attention to detail, whereas the right hemisphere operates with sustained, broad, open, and vigilant attention. Additionally, the four macrosystems operate on two different levels of complexity (Kazén et al., 2015; Kuhl, 2000b): high-level self-representations (IM and EM) and elementary perceptions (IBC and OR). Kuhl states that interplay between these four systems is primarily influenced by modulation of positive and negative affect. Affect is generated by changes in the discrepancy between actual and desired states on the sub-conscious level of needs and is not always consciously accessible (Kuhl, 2018).

To outline the distinct functionality and the interplay of the four systems, we will focus on two fundamental personality processes that, according to PSI theory, are crucial for the functioning of a person: behaviour-oriented volitional control and cognition- and experience-oriented self-growth (Alsleben \& Kuhl, 2011). Volitional control refers to the process that enables a person to enact difficult (i.e. non-routine) intentions and requires communication between IM and IBC, whereas self-growth (synonymously selfdevelopment) refers to the process that enables a person to integrate new experiences into a coherent self-system and requires communication between OR and EM. Taken together, the processes address a central aspect of many career counselling interventions: How can clients successfully implement their career goals (volition control) and thereby undergo a self-congruent career development (self-growth)? 
Table 2. Volitional control and self-growth processes according to the PSI theory (simplified).

\begin{tabular}{|c|c|c|}
\hline & $\begin{array}{l}\text { Volitional Control } \\
\text { (Self-control): } \\
\text { Concrete behaviour }\end{array}$ & $\begin{array}{l}\text { Self-growth } \\
\text { (Self-development, self- } \\
\text { regulation): } \\
\text { Cognitions and experiences }\end{array}$ \\
\hline $\begin{array}{l}\text { High-level self- } \\
\text { representations }\end{array}$ & $\begin{array}{l}\text { Intention Memory (IM) } \\
\text { - } \text { making abstract plans } \\
\text { - explicit and analytic, sequential } \\
\text { information processing (left } \\
\text { hemisphere) }\end{array}$ & $\begin{array}{l}\text { Extension Memory (EM) } \\
\text { - feeling the integrated self } \\
\text { - mainly implicit and holistic, } \\
\text { parallel information processing } \\
\text { (right hemisphere) }\end{array}$ \\
\hline $\begin{array}{l}\text { Affect } \\
\text { modulation }\end{array}$ & $\begin{array}{l}\text { First modulation assumption: } \\
\text { - positive affect }(\mathrm{A}+) \text { fosters IBC } \\
\text { - downregulating positive affect } \\
(\mathrm{A}(+)) \text { fosters } \mathrm{IM}\end{array}$ & $\begin{array}{l}\text { Second modulation assumption: } \\
\text { - negative affect (A-) fosters OR } \\
\text { - downregulating negative affect } \\
\text { (A(-)) fosters EM }\end{array}$ \\
\hline $\begin{array}{l}\text { Elementary } \\
\text { perceptions }\end{array}$ & $\begin{array}{l}\text { Intuitive Behaviour Control (IBC) } \\
\text { - performing routines, executing } \\
\text { activities } \\
\text { - implicit and holistic, parallel } \\
\text { information processing (right } \\
\text { hemisphere) }\end{array}$ & $\begin{array}{l}\text { Object Recognition (OR) } \\
\text { - } \text { identifying details } \\
\text { - } \quad \text { explicit and analytic, sequential } \\
\text { information processing (left } \\
\text { hemisphere) }\end{array}$ \\
\hline
\end{tabular}

Volition control is primarily affected by the interplay of two macrosystems: IM (analytic, high-level) and IBC (holistic, elementary). Note the contrasting processing mode and level of the systems involved. IM is necessary to formulate abstract plans (e.g. working out a job application strategy), pursue goals (e.g. finding a job in another industry), and retain intentions that cannot or should not be implemented immediately (e.g. implementing a middle-term strategy or searching for the right job to apply for). IBC is essential for implementing intended actions and therefore helps transform plans into concrete action. IM and IBC operate as antagonists: During planning, the act of implementation must be inhibited to prohibit rash actions. On the other hand, planning 
must be stopped when the moment is opportune for action. Therefore, as one system is activated, the other is simultaneously inhibited. Routine actions, incidentally, are implemented by IBC on its own and do not require the transfer of an explicit intention from IM.

According to the first modulation assumption of the PSI theory, it is positive affect that modulates the interplay between the high-level IM and the elementary IBC. Positive affect fosters IBC while inhibiting IM. Downregulation of positive affect, which requires frustration tolerance, fosters IM while inhibiting IBC. Flexible regulation of positive affect is facilitated if an intention is supported by the motives ${ }^{1}$ of power and particularly achievement (Alsleben \& Kuhl, 2011; Kuhl, 2018): High achievement motivation implicitly ensures that the interplay of IM and IBC works properly. Highly achievement motivated people are well equipped to tackle difficult tasks and face complex challenges. Difficulties along the way implicitly lead to downregulation of positive affect and activation of IM. Once planning is done, the prospect of accomplishing a difficult intention re-induces positive affect and triggers active implementation. For less achievement motivated persons, social support or active imagination of other positive aspects and feelings related to goal-achievement can help to induce the positive affect

${ }^{1}$ Very interestingly and congruent with our approach in combining PSI theory with Life Design, Kuhl (2018) suggests that motives should be measured qualitatively: 'Motives develop from an extensive web of autobiographical episodes, i.e. from personal "stories." The high level of cognitive integration characteristic of motives is best attained by asking respondents to generate stories of their own' (p. 567). Even though the practical implications of the implicit and explicit motives for career counselling are considerable, we will not further elaborate on motives throughout the article because of space restrictions. For an in-depth view of the interplay of motives and affect modulation, see Alsleben and Kuhl (2011). 
needed to activate IBC. Additionally, note that according to Kuhl (2000b) 'Forming abstract rather than concrete intentions permits greater flexibility and adaptability to future conditions that cannot be fully anticipated' (p. 682). We believe that this can be especially important in the domain of career counselling. Accordingly, we lay a special focus on the crucial step of formulating visions and abstract strategies when working with our clients, before elaborating on concrete plans.

In summary, effective volitional control requires the ability to switch back and forth between IM and IBC. Thus, making coherent plans and implementing them, even if severe challenges arise on the way, is facilitated. Flexible up- and downward modulation of positive affect is of great importance in this process. After having demonstrated the complex cognitive and affective functional processes that underlie volitional control, we will now turn to the processes affecting self-growth.

Self-growth is primarily affected by the interplay of the two other macrosystems: EM (holistic, high-level) and OR (analytic, elementary). Again, the two systems involved are contrasting in processing mode and level. Kuhl (2000b) describes EM as follows: 'Extension memory is the repository for extended networks of remote semantic associations such as meaningful experiences, options for action, personal values, and many other aspects of the "integrated self" (p. 670). EM is about feeling or having a sense of self within one's social context. In this way, EM offers the best overview of what a person wants (Kuhl, 2000b). In the context of career counselling, EM is related to questions such as: What makes my vocational life meaningful and in line with my personal values, needs, or interests? OR serves as a detector of unexpected or undesired external objects or internal thoughts (e.g. internal thoughts about a dispute with one's supervisor or a lack of meaning at work) and enables contemplation of the object out of 
context. The terms unexpected and undesired relate to the holistic representations of the rather implicit EM. OR and EM, just like IM and IBC, operate as antagonists.

According to Kuhl's second modulation assumption, negative affect modulates the interplay between EM and OR. Negative affect activates OR and inhibits EM, thereby blocking access to the integrated self within EM. This can result in career counselling clients limiting all their thoughts to specific undesired objects (e.g. a dispute with a supervisor or their salary) through their OR and losing sight of other relevant aspects of their vocational life. Downregulation of negative affect grants access to EM while inhibiting OR. For self-growth, both OR and EM are indispensable. OR supplies the input required for the integrated self, which is part of the EM. The term integrated refers to the ability of the integrated self to reconcile even conflicting information, such as good and bad experiences or conflicting motives. A person can only learn from painful experiences by first tolerating negative affect. Kuhl calls this form of coping self-confrontation. It involves looking at the painful experience while negative affect activates OR, followed by downregulation of negative affect and integration of the painful object into EM. This integration makes it possible to avoid repeating the same painful experience in the future.

In summary, effective self-growth derives from the ability to switch back and forth between EM and OR. Thus, details identified by OR, especially distressing experiences, are integrated into EM and the integrated self can grow continuously. Flexible up- and downward modulation of negative affect is of great importance in this process. $^{2}$

\footnotetext{
${ }^{2}$ Kuhl emphasizes the positive precondition of action-orientation compared to state-orientation as 'state-oriented individuals report having uncontrollable ruminations following failure experiences' whereas 'action-oriented individuals have no difficulty disengaging from (i.e.
} 
Finally, we would like to point to the important impact the two processes have on each other. On one hand, effective self-growth impacts volition control by being a precondition for setting self-congruent goals. On the other hand, effective volition control leads to action and thus to positive and negative experiences that enrich EM. The richer in experiences, the better EM can support self-congruence. To strengthen self-clarity in career counselling, bringing EM to an explicit and vocalised level and thereby integrating important information from OR can be of great importance. Visualising one's EM - as intended with the Vocational ID - can serve as a compass representing key elements of a career counselling client's self. Self-congruent goals facilitate volition because they are supported by the mainly implicit motives and values represented in EM. Lack of access to EM due to persevering negative affect may result in incongruent goals. Kuhl (2000b, 2018) speaks of extrinsic introjects or self-infiltration when one's own wishes, goals, and choices are confused with those of others (e.g. parental or societal expectations) and therefore are not fully integrated in the EM.

\section{Identity and self-development from a PSI theory perspective}

With regard to the great importance of affect modulation for volitional control and selfgrowth, Kuhl (2018) states that 'excessive stress and the associated negative affect inhibit high-level holistic processing (self-access), whereas positive affect plays a key role in facilitating behaviour' (p. 558). According to PSI theory, identity and self-development are based upon the complex interplay of the four cognitive systems as well as the affective modulations depicted above. Volitional control and self-growth require activity of both the right and the left hemisphere. Regarding Kuhl's modulation assumptions, we can

“downregulating") unwanted thoughts and emotions even following aversive experiences' (2000b, p. 672). 
conclude that career counselling clients need to be able to actively modulate positive and/or negative affect to be successful in setting and implementing self-congruent goals and continuously developing their self and identity. Career counselling clients often state that they more easily operate either in an analytic/left hemispheric (i.e. tend to make plans based on thorough analysis) or in a more holistic/right hemispheric way (i.e. tend to act spontaneously and based on intuition). Furthermore, clients differ in the basic motives (achievement, power, affiliation, or freedom) that shape their perception and behaviour (Alsleben \& Kuhl, 2011). By analysing these individual dispositional preferences in combination with the clients' depiction of their central issue, PSI theory can provide counsellors (and clients) with ideas for bespoke interventions for downward or upward regulation of positive or negative affect.

Kuhl (2000b) established eight steps that are crucial for successful selfdevelopment: (1) problem perception, (2) realistic goal setting and identification with the goal, (3) persistent goal pursuit, (4) attentive monitoring of available cognitive, emotional, and situational resources, (5) effective self-management of emotional and motivational states, (6) planning and problem-solving, (7) energetic initiative and implementation of plans, and (8) effective use of performance feedback. Implementation of the eight steps requires flexible and adaptive use of all the four macrosystems, supported by effective affect-regulation. Referring to the Vocational ID, we will emphasize the processes of self-growth and volitional control that underlie these eight steps and adapt them to our case study later in this paper.

\section{The Vocational ID - linguistic and visual aspects}

We designed the Vocational ID to support effective career counselling and as a facilitator for working with the CCI to form the various aspects of the six questions of the CCI into a consistent and tangible illustration of the life portrait. Furthermore, we use the 
Vocational ID as a framework to integrate the PSI theory into the Life Design perspective represented by the four phases of the Career Construction Theory (construction, deconstruction, reconstruction, and co-construction). We will now elaborate further on our framework that relates the Vocational ID to the Life Design perspective as well as to the PSI theory and introduce the different areas of the ID depicted in Figure 1. Subsequently, we will discuss our case study Chris.

\section{«Vocational ID»}

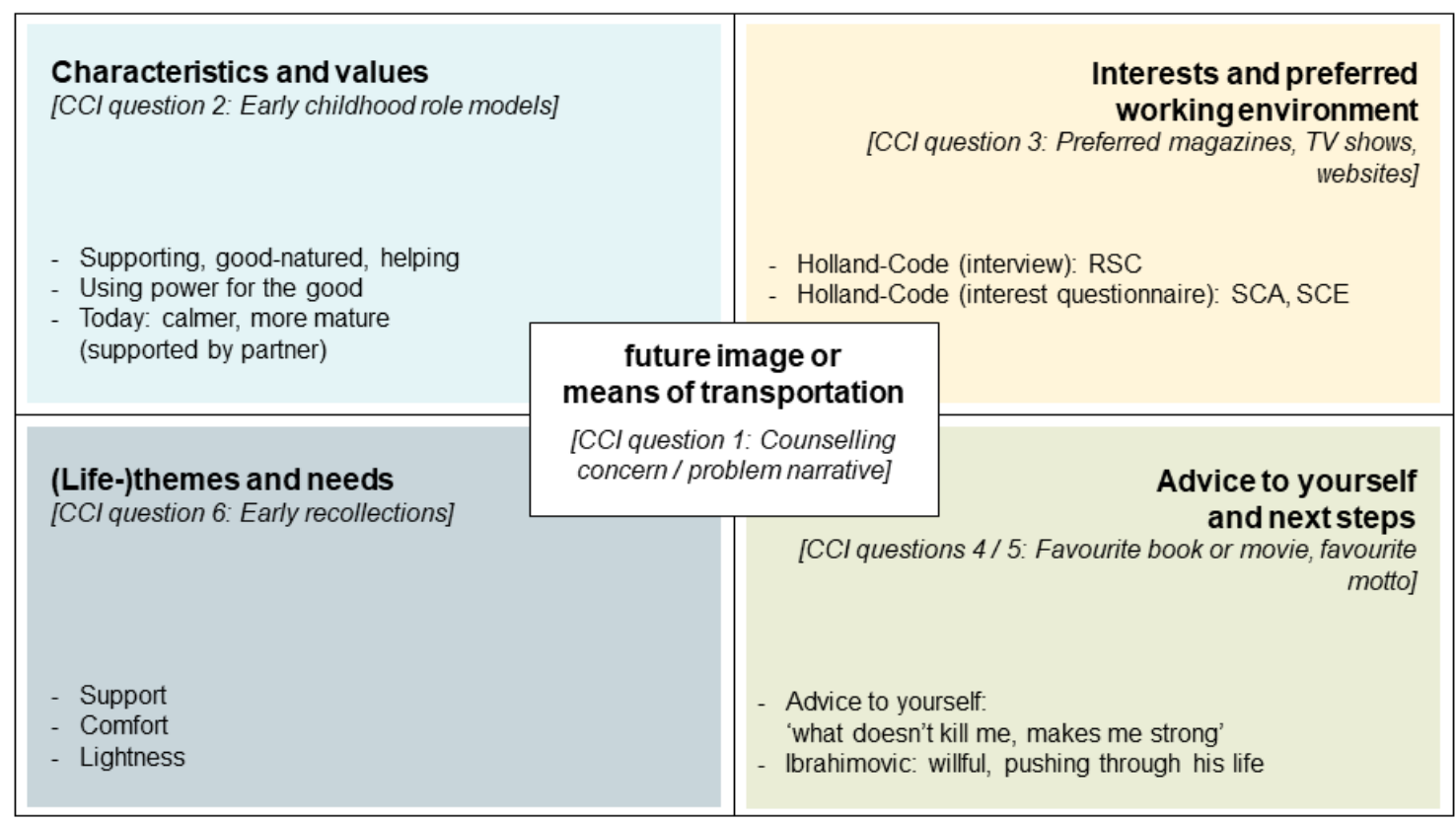

Figure 1. Vocational ID of Chris including attribution to the six questions of the CCI.

The Vocational ID includes four areas, which can be attributed, albeit partially overlapping, to the answers to the six questions of the CCI. Consequently, the Vocational ID represents the different facets of the self according to the Life Design perspective (see Table 1) and serves as a structured visualisation of the client's life portrait, comprising occupational plot, career theme, and character arc. In the middle, there is space for a photograph or picture chosen by the client that symbolises either the desired future (e.g. scenery, symbol) or a characterising means of transportation (e.g. 
airplane, bicycle) that lets the client reach the counselling concern (question 1). Clients can make their own drawing, take a photograph, or search the internet for a fitting image.

As an additional option, we developed a public domain counselling platform containing so-called resource images. ${ }^{3}$ We instruct clients to select and bundle a set of resource images according to their individual preferences. In a self-directed process, clients select their most appealing resource image and make a reflection thereof. Clients oftentimes choose their resource image as a symbol for their Vocational ID. Taylor and Savickas (2016) showed that the combination of the CCI with Pictorial Narratives, a very similar qualitative approach in which clients are asked to draw their current situation as well as their desired future situation, can be very useful.

Table 3 contains the framework that relates the Vocational ID to the Life Design paradigm and the PSI theory. We arrange the framework along the four phases of the Life Design counselling process according to the Career Construction Theory and differentiate between the stages of establishing the ID, ranging from construction to reconstruction, and working with the ID, primarily consisting of the co-construction phase. In our framework, conducting the CCI and working with concepts of the PSI theory play different roles within different phases of the counselling process: (1) The CCI is crucial to establishing the ID, wherein important aspects of the career client's self are made visible and tangible by means of the Vocational ID. (2) Afterwards, while working with the ID in the co-construction phase, clients make decisions (deciding) and transform their decisions into concrete actions (doing) (Savickas, 2011a). During this stage, the processes of self-growth and volitional control as outlined within the PSI

\footnotetext{
${ }^{3}$ see www.laufbahndiagnostik.ch/en/tools
} 
theory are crucial and provide career counsellors (and clients) with helpful insights. We will now introduce the practical applications of the Vocational ID by illustrating the case of Chris and further explicating the above-mentioned processes and theories. In line with our framework, we have divided the case study into the stages of establishing the ID and working with the ID.

Table 3. Vocational ID framework integrating Life Design counselling process, CCI, and PSI theory.

\begin{tabular}{|l|l|l|}
\hline Vocational ID stages & Establishing the ID & Working with the ID \\
\hline Life Design counselling phases & Construction, & Co-construction \\
Construction Theory) & reconstruction, and & \\
\hline Role of CCI & Information gathering and & Minor role \\
& poconstruction of life & Vocational ID. \\
\hline Role of PSI theory & Minor role & Facilitating deciding \\
& & and doing by analysing \\
& & the client's volitional \\
& & control and self-growth \\
& & \\
\hline
\end{tabular}

\section{The case of Chris: Establishing the Vocational ID}

Chris (name changed), a 39-year-old former professional athlete, was on his way to selfemployment at the time of his consultation. Together with his partner and a colleague he was in the process of founding a company in the field of sports care (mental training, 
fitness, nutrition). For financial security, Chris was also looking for part-time employment. His counselling concerns (question 1) were related to taking positive steps in achieving his goal of self-employment as well as to learning more about himself.

The deconstruction of the contents of the CCI was conducted along the four areas in the Vocational ID (see Figure 1). We will subsequently present Chris' answers to the six CCI questions (construction phase). Chris reported the following three childhood memories (question 6), from which his specific life themes and unfulfilled needs could be drawn: In his first memory, Chris is about two years of age. He wakes up thirsty and calls for his father, who brings him water. His title for this recollection was 'Help! I need something'. The second situation he could remember was wanting to be pushed in a baby carriage. Although his mother thought he was old enough to walk, he was permitted to sit in the baby carriage. He entitled this memory with 'I am too comfortable'. In the third memory, Chris told of being at home at the age of three or four with his older cousin and his friends while his parents were out. The children made a ruckus until a neighbour came by, reprimanded them, and pulled Chris' ear. His headline for this story was 'Whoop it up'. From these three recollections, Chris identified the life themes support, comfort and lightness that hint at his unfulfilled needs and add meaning to his personal story. He would have hoped for more support in some situations, especially from his parents. He noted that giving support to others should play an important role in both his professional and private life. To overcome his need for comfort, Chris sometimes requires time pressure or an impulse by external motivators but, ultimately, he is very reliable, works accurately, and delivers results on time. As a balance to his professional commitment, he sees celebrations and a certain lightness (in terms of an easy-going attitude) as outlets to relieve stress. Even though a lot has changed since his childhood and Chris has learned 
to cope positively with his life themes, support and lightness are still important topics to him.

Characteristics and values that are applicable to Chris today could be identified from his childhood role models (question 2). One role model was the animated character He-Man, which he described as being tall, blond, muscular and good-natured. United with his sword and tiger, the figure transformed into a hero to fight against evil. Chris also helps and supports others and for him, high-performance sport could be seen as an area that gives him extra powers, similar to what the sword does to He-Man. He said that it was important to him to show his strengths, especially in his company or as a coach. Looking at Chris' second role model, a neighbour and later friend, one can identify an opposing development in the two personalities: Chris described the friend as a quiet person who had gradually opened up and was now a joker. Chris himself had become calmer over the years. His third role model was the Brazilian football player Zico. Chris especially admired Zico's gameplay as a central player and playmaker, and the way he could unfold his strengths in the team. In his own life, Chris could see himself as the central driving force in his company and realized his ability to always see the bigger picture. This is also important to him in his role as a coach.

For the question about favourite journals, TV shows or websites (question 3), which relates to interests and preferred working environment, Chris listed 'GQ', 'Men's Health', 'Facebook', as well as several daily newspapers and sports shows. In the magazines, he is particularly interested in fashion, nutrition, health, trends, and sports. The daily newspaper provides him with short, current information. Sports shows are relevant to him in terms of his own athletic career as well as his occupational future in the field of mental coaching. According to Savickas (2015b), this CCI question also refers to Holland's (1997) RIASEC model. Chris and his career counsellor derived the 
Code RSC from Chris' answers to this question. Additionally, Chris completed the German version of the Oregon Vocational Interest Scales (ORVIS; Pozzebon, Visser, Ashton, Lee, \& Goldberg, 2010). ${ }^{4}$ Figure 1 shows that Chris' RIASEC code from the explicit interest inventory (SCA, SCE) differs from the rather implicit RIASEC code worked out with the CCI (RSC). This supports the goal of the ID, which is to portray both implicit and explicit aspects of the self. Discrepancies between these aspects can then be brought up based on the Vocational ID and be discussed with the client.

Finally, the answers to the two questions about favourite book or movie (question 4) and about favourite motto (question 5) relate to advice to oneself and possible next steps. Chris chose the biography of the football player Zlatan Ibrahimovic as his current favourite book. Chris characterised him as a strong-willed person who had to fight his way through, especially during his youth. He grew up in poor conditions but was always supported by his father. This illustrates parallels to Chris' life theme support. He would have wished for more support from his father, but also pushed himself and made his own athletic decisions, including some that went against the wishes of his parents. He was able to overcome difficult phases in life, for example sporting injuries, with the help of his life motto 'what does not kill me, makes me strong'. This motto emphasizes perseverancehighly important in performance sport-and an optimistic way of tackling challenges. Chris knows he will end up stronger after difficult situations. He will consistently be confronted with such situations during his self-employment, but he will be able to face them calmly.

To make the different elements of the CCI more real, tangible and visible to Chris, and to mark progression from the reconstruction into the co-construction phase, the

\footnotetext{
${ }^{4}$ The German version of the ORVIS has been translated at our institute.
} 
results from the CCI process (and from other parts of the counselling process such as the interest inventory) were gathered in the Vocational ID together with Chris. By seeing at a glance his life themes and needs, individual characteristics and values, interests and preferred surroundings, as well as concrete next steps, Chris gained new insights and understanding into his past experiences, current situation, and possible future. In other words, he further developed his inner compass that can support him in making decisions and planning concrete actions. As the ID explicitly relates to both verbalized and visual aspects, it can help him switch more easily from left hemispheric to right hemispheric processes.

\section{The case of Chris: Working with the Vocational ID}

In terms of the PSI theory, Chris' Vocational ID reflects the aspects of the integrated self (EM) that were made explicit during the CCI process. Additionally, the self-chosen future image or means of transportation itself serves as a holistic and visual representation of the EM. As a pictorial illustration, Chris chose a scooter as his appropriate means of transportation. By choosing a means of transportation instead of a future image he implicitly decided to focus on volition control. The choice of a future image would have focused more on reflecting the characteristics of the desired (vocational) future and therefore on identifying the underlying needs, motives, interests, or (life-) themes related to EM and self-growth. With the scooter, Chris connects and anchors the way of locomotion important and opportune for him in his current situation: flexible, individual, yet fast.

With regard to Chris' situation, we want to point out key elements of the Vocational ID that can contribute to (1) self-growth (second modulation assumption of the PSI theory) and (2) effective volitional control (first modulation assumption) within the co-construction phase. 
(1) Self-growth (OR/EM, modulated by negative affect): Chris aims at being selfemployed as a consultant within the sports domain. Although he had already established his goal before career counselling, he was able to review it for congruency with his integrated self (EM). It was only after self-confrontation with his life theme support, though, that his integrated self could fully serve in this review for self-congruence. The lack of support from Chris' parents was a painful memory, an undesired object within OR. By contemplating this memory together with his counsellor, Chris realized that despite this difficulty he had become a successful athlete and that he felt forgiveness for his parents. Thus, he could downregulate negative affect, gain access to EM, and complete his integrated self with his life theme support, which was no longer linked to pain. Altogether, his Vocational ID contains many aspects that support his professional goal (e.g. his newly integrated (life-) theme support, his personal characteristics supporting, good-natured, helping, as well as his social interest). To gain access to EM in the future, Chris has two strategies to downregulate negative affect: First, the teamwork with his partner and a colleague relieves him from stress, which is a form of downregulating negative affect. Second, his favourite motto in his Vocational ID (what doesn't kill me, makes me strong) gives him powerful additional orientation.

(2) Volitional control (IM/IBC, modulated by positive affect): In any large undertaking, such as Chris becoming self-employed, frustrations in the form of downregulated positive affect can arise because of severe obstacles hindering goal attainment. Chris reported that he prefers to operate more in a holistic, spontaneous mode than in an analytic mode. His life theme lightness confirms this self-assessment. Therefore, switching to IM and tolerating downregulated positive affect can be difficult for him. With the aid of his counsellor, he became aware of this difficulty. This insight prompted him to regulate his affect more consciously and to sustain IM's planning mode 
as long as needed. His chosen picture of the scooter can also help him in this regard: If Chris wants to reach (on his scooter) his abstract "destination" of being a consultant in the sports domain, he needs to stop from time to time to study the map and find the best route. This image helps Chris counteract his tendency toward immediate action and switch to planning mode more easily. Additionally, his strong motto as well as the story of Ibrahimovic support his volition control. Thanks to the Vocational ID, he has picture, motto and the narrative of Ibrahimovic always readily and visually at hand. This helps him tolerate downregulated positive affect and regain positive affect to overcome potential upcoming obstacles.

During his career counselling sessions, Chris was thus able to plan things and set things in motion at the right time, including finishing the administrative work and coordinating the opening of his office rooms. His vision of being self-employed as a consultant within the sports domain is a concretion derived from his life themes, interests and resources summarised on his Vocational ID. This leads him to concrete, meaningful actions to make his vision a reality. After the counselling sessions, Chris stated that with the aid of the Vocational ID, he achieved his counselling concerns of taking concrete steps towards self-employment and of learning more about himself.

\section{Conclusion}

We introduced the Vocational ID as a facilitating tool for career counselling based on the Life Design perspective, especially the Career Construction Theory. We emphasized the integration of linguistic and visual aspects of the ID. While linguistic elements embrace the explicit, analytic, and left hemispheric processes accompanying career counselling, visual aspects such as the Vocational ID as a whole or the self-chosen image cover the rather implicit, holistic, and right hemispheric processes. Working with the Vocational ID allows switching from one perspective to the other and - most importantly - allows 
combining both processes within a single tool to support career counselling matters such as working on vocational identity, goal-setting (deciding), and goal-implementation (doing). The ID provides a framework that integrates cognitive and affective aspects relevant for career development, which always pertains to questions of transition and change. Transition and change can only successfully take place when clients possess or can establish an inner compass indicating in which direction to proceed and how to overcome upcoming obstacles.

The Life Design paradigm (applied through the six open questions of the CCI) represents an effective way to build and strengthen a career counselling client's compass that can then be visualized by compiling the Vocational ID. Savickas (2011a) states that in the co-construction phase, 'clients must perform their new meaning' (p. 139) in making a decision based on the key findings of the counselling process (deciding). Furthermore, they should transform their choice into concrete actions for the next days, weeks, and months to come (doing). According to Savickas (2011a), clients' reasons for struggling in doing differ. Some encounter challenges because of negative emotions, such as anxiety, that accompany their phase of transition. For those clients, PSI theory represents a framework that enables interventions focused on client-centred self-growth by targeting the downregulation of negative affect and access to the integrated self (EM). Other clients struggle with 'reality that thwarts easy action' (Savickas, 2011a, p. 140). Here, PSI theory rather emphasizes interventions that rely on solution-focused volition control that is related to positive affect. The Vocational ID serves as a facilitator to visualize those particular characteristics of a career counselling client that are related to both self-growth and volitional control. This shows that the interplay of the CCI and PSI theory through the Vocational ID can cover a broad range of relevant career counselling topics. 
The Vocational ID can also be adopted to other career counselling approaches such as questionnaire-oriented matching (Vocational Guidance), where the ID can be applied as an aggregation of the most important findings of the person-environment fitting process. We therefore also use the Vocational ID to embrace and highlight the findings of psychometric questionnaires. Characteristics of the personality, competencies, interests, values, and motives can be recorded in the corresponding sections of the Vocational ID (see Figure 1). Counsellors that work with their clients on developing (Career Education and Coaching) and defining core competencies can also transfer the relevant findings to the Vocational ID. Whereas the two top sections of the Vocational ID cover general aspects of matching, guiding, and self-actualisation, the bottom sections of the Vocational ID represent important facets of life designing such as crucial (life-) themes and advice to oneself on how to overcome obstacles (see Figure 1).

As process-oriented career counselling has much to do with exploration and concrete action, we also want to point to the uses of the Vocational ID when working with the Cognitive Information Processing (CIP) approach and the CASVE cycle (Communication, Analysis, Synthesis, Valuing, Execution), both proposed by Sampson Jr., Peterson, Lenz, and Reardon (1992), as well as with the Social Cognitive Career Theory (SCCT; Lent \& Brown, 2013; Lent, Brown, \& Hackett, 1994). Furthermore, we would like to mention the Career Flow approach introduced by Niles, Amundson, and Neault (2011) differentiating between certain stages of the counselling process: selfreflection, self-clarity, envisioning, decision-making, goal-setting, planning, implementing, and adapting. Career counsellors working with these approaches can use the Vocational ID in different stages of the counselling process, to retain the relevant aspects of their clients and their occupational knowledge as well as the crucial 
metacognitions that are related to decision-making, other forms of information processing, and goal-implementation.

In summary, the Vocational ID is a multifaceted and flexible tool that can be used not only when working with the CCI or the PSI theory, but with a multitude of career counselling approaches. In combining elements of analytic thinking and holistic feeling and making elements of the implicit self visible and tangible, it offers a way of bringing up important aspects during career counselling sessions that can help clients further develop and strengthen their inner compass and their professional goals. In our experience, clients also very much appreciate the fact that with the Vocational ID, they have a tangible and comprehensible tool at hand that they can look at and use anytime, even weeks, months, or years after their counselling sessions. This helps them keep important aspects of their self in mind for difficult professional situations and new challenges, even far in the future.

We look forward to further developing and expanding this versatile tool. Contributions and suggestions are very much appreciated and should be directed to the corresponding author.

\section{Acknowledgments}

We thank the following colleagues for their valuable contributions to this article: Ladina Schmidt of the IAP Institute of Applied Psychology of the ZHAW co-developed the Vocational ID together with the corresponding author. Sonja Schlaepfer, Noemi Blumer, and Ida Marie Mueller edited our case study, being students or interns at that time. We would also like to thank an anonymous reviewer who gave us insightful feedback on the Life Design section. 


\section{Declaration of interest statement}

No potential conflict of interest was reported by the authors.

\section{References}

Alsleben, P., \& Kuhl, J. (2011). Touching a person's essence: Using implicit motives as personal resources in counseling. In W. M. Cox \& E. Klinger (Eds.), Handbook of motivational counseling: Goal-based approaches to assessment and intervention with addiction and other problems (pp. 109-129). Wiley-Blackwell. doi.org/10.1002/9780470979952.ch5

Broonen, J.-P. (2015). Motivation and volition in vocational psychology: An action control perspective. In R. A. Young, J. F. Domene, \& L. Valach (Eds.), Counseling and action. Toward life-enhancing work, relationships, and identity (pp. 69-89). New York, NY: Springer.

Holland, J. L. (1997). Making vocational choices: A theory of vocational personalities and work environments (3rd ed.). Odessa, FL: Psychological Assessment Resources. Hunt,.

Kazén, M., Kuhl, J., \& Quirin, M. (2015). Personality interacts with implicit affect to predict performance in analytic versus holistic processing. Journal of Personality, 83(3), 251-261. doi.org/10.1111/jopy.12100

Kuhl, J. (2000a). A functional-design approach to motivation and self-regulation: The dynamics of personality systems and interactions. In M. Boekaerts, P. R. Pintrich, \& M. Zeidner (Eds.), Handbook of self-regulation (pp. 111-169). San Diego: Academic Press. doi.org/dx.doi.org/10.1016/B978-012109890-2/50034-2

Kuhl, J. (2000b). The volitional basis of personality systems interaction theory: Applications in learning and treatment contexts. International Journal of Educational Research, 33(7-8), 665-703. doi.org/10.1016/S0883-0355(00)00045- 
Kuhl, J. (2001). Motivation und Persönlichkeit. Göttingen: Hogrefe.

Kuhl, J. (2018). Individual differences in self-regulation. In J. Heckhausen \& H. Heckhausen (Eds.), Motivation and action (3rd ed., pp. 529-577). Cham: Springer. doi.org/10.1093/oxfordhb/9780199642342.013.034

Lent, R. W., \& Brown, S. D. (2013). Social cognitive model of career self-management: Toward a unifying view of adaptive career behavior across the life span. Journal of Counseling Psychology, 60(4), 557-568. doi.org/10.1037/a0033446

Lent, R. W., Brown, S. D., \& Hackett, G. (1994). Toward a unifying social cognitive theory of career and academic interest, choice, and performance. Journal of Vocational Behavior, 45(1), 79-122. doi.org/doi.org/10.1006/jvbe.1994.1027

McAdams, D. P., \& Olson, B. D. (2010). Personality development: Continuity and change over the life course. Annual Review of Psychology, 61, 517-542. doi.org/10.1146/annurev.psych.093008.100507

McGilchrist, I. (2009). The master and his emissary: The divided brain and the making of the western world. New Haven and London: Yale University Press.

Niles, S. G., Amundson, N. E., \& Neault, R. A. (2011). Career flow: A hope-centered approach to career development. Boston, MA: Prentice Hall.

Pozzebon, J. A., Visser, B. A., Ashton, M. C., Lee, K., \& Goldberg, L. R. (2010). Psychometric characteristics of a public-domain self-report measure of vocational interests: The oregon vocational interest scales. Journal of Personality Assessment, 92(2), 168-174. doi.org/10.1080/00223891.2010.516712

Quirin, M., Gruber, T., Kuhl, J., \& Düsing, R. (2013). Is love right? Prefrontal resting brain asymmetry is related to the affiliation motive. Frontiers in Human Neuroscience, 7. doi.org/10.3389/fnhum.2013.00902 
Quirin, M., Meyer, F., Heise, N., Kuhl, J., Küstermann, E., Strüber, D., \& Cacioppo, J. T. (2013). Neural correlates of social motivation: An fMRI study on power versus affiliation. International Journal of Psychophysiology, 88(3), 289-295. doi.org/10.1016/j.ijpsycho.2012.07.003

Sampson Jr., J. P., Peterson, G. W., Lenz, J. G., \& Reardon, R. C. (1992). A cognitive approach to career services: Translating concepts into practice. The Career Development Quarterly, 41(1), 67-74. doi.org/10.1002/j.21610045.1992.tb00360.x

Savickas, M. L. (1989). Career style assessment and counseling. In T. Sweeney (Ed.), Adlerian counseling: A practical approach for a new decade (3rd ed., pp. 289329). Muncie, IN: Accelerated Development.

Savickas, M. L. (2011a). Career counseling. Washington, DC: American Psychological Association.

Savickas, M. L. (2011b). Constructing careers: Actor, agent, and author. Journal of Employment Counseling, 48(4), 179-181.

Savickas, M. L. (2011c). New questions for vocational psychology: Premises, paradigms, and practices. Journal of Career Assessment, 19(3), 251-258. doi.org/10.1177/1069072710395532

Savickas, M. L. (2011d). The self in vocational psychology: Object, subject, and project. In P. J. Hartung \& L. M. Subich (Eds.), Developing self in work and career: Concepts, cases, and contexts (pp. 17-33). Washington, DC: American Psychological Association.

Savickas, M. L. (2012a). Life design: A paradigm for career intervention in the $21 \mathrm{st}$ century. Journal of Counseling and Development, 90(1), 13-19. doi.org/10.1111/j.1556-6676.2012.00002.x 
Savickas, M. L. (2012b). The 2012 Leona Tyler Award address: Constructing careers actors, agents, and authors. The Counseling Psychologist, 41, 648-662. doi.org/10.1177/0011000012468339

Savickas, M. L. (2013). Career construction theory and practice. In S. D. Brown \& R. W. Lent (Eds.), Career development and counseling. Putting theory and research to work (2nd ed., pp. 147-183). Hoboken, N.J.: John Wiley \& Sons.

Savickas, M. L. (2015a). Career counseling paradigms: guiding, developing, and designing. In P. J. Hartung, M. L. Savickas, \& W. B. Walsh (Eds.), APA handbook of career intervention: Vol. 1. Foundations (Vol. 1, pp. 129-143). Washington, DC: American Psychological Association. doi.org/10.1037/14438-000

Savickas, M. L. (2015b). Life-design counseling manual. Rootstown, OH. Retrieved from www.vocopher.com

Savickas, M. L., Nota, L., Rossier, J., Dauwalder, J.-P., Duarte, M. E., Guichard, J., ... van Vianen, A. E. M. (2009). Life designing: A paradigm for career construction in the 21 st century. Journal of Vocational Behavior, 75(3), 239-250. doi.org/10.1016/j.jvb.2009.04.004

Taylor, J. M., \& Savickas, S. (2016). Narrative career counseling: My career story and pictorial narratives. Journal of Vocational Behavior, 97, 68-77. doi.org/10.1016/j.jvb.2016.07.010 
Marc Schreiber, $\mathrm{PhD}$ is a professor at IAP Institute of Applied Psychology, Zurich University of Applied Sciences (ZHAW) where he works as a researcher and lecturer in Psychology and Career Counselling as well as a career counsellor. He is responsible for the Master of Advanced Studies in Occupational, Educational and Career Guidance Counselling at the IAP.

Adrian Gschwend holds a Bachelor of Law and a Master of Advanced Studies in Occupational, Educational and Career Guidance Counselling, both from the Zurich University of Applied Sciences (ZHAW). His professional, academic, and research interests include vocational and narrative identity, constructivist and social constructionist paradigms in career counselling, and personality development. Adrian works as a self-employed career counsellor with a special emphasis on life-design counselling in St. Gallen and Zurich, Switzerland.

Marie-Louise Susanne Iller holds a Bachelor of Science in Applied Psychology from Zurich University of Applied Sciences (ZHAW) and is close to completing her studies for the Master of Science in the same discipline. Her specialisation is Developmental and Personality Psychology. Currently, she works as a research assistant at IAP Institute of Applied Psychology. She is interested in qualitative and quantitative assessment of personality and her professional goal is career counselling. 